\title{
Oncologic long-term outcome of single-incision laparoscopic surgery (SILS) for colorectal cancer
}

\author{
Andreas D. Rink ${ }^{1,2}\left(\right.$ D $\cdot$ Vitaly Golubev $^{2} \cdot$ Boris Vestweber $^{3} \cdot$ Claudia Paul $^{2} \cdot$ Hauke Lang $^{1} \cdot$ Karl-Heinz Vestweber $^{2}$
}

Accepted: 2 March 2021 / Published online: 16 March 2021

(C) The Author(s) 2021

\begin{abstract}
Purpose Single-incision laparoscopic surgery (SILS) has been introduced as a less invasive alternative to multi-port laparoscopic surgery (MLS). MLS is widely accepted for the treatment of colorectal cancer, but there remains minimal evidence for the use of SILS. Thus, we compared both short- and long-term outcomes of SILS and open surgery (OS) in matched cohorts of colorectal cancer patients.

Methods Some 910 patients had colorectal resections for cancer between 2006 and 2013, and 134 of them were operated on using SILS. Eighty of these SILS patients were compared to a cohort of patients who had open surgery that were matching in tumour stage and location, type of resection, sex, age and ASA Score. Disease-free survival at 5 years (5y-DFS) was the primary endpoint; morbidity and hospitalization were secondary parameters. The role of surgical training in SILS was also investigated. Results Clavien Dindo $\geq \mathrm{IIIb}$ complications occurred in $13.8 \%$ in both groups. 5y-DSF were $82 \%$ after SILS and $70 \%$ after OS ( $p$ $=0.11$ ). Local recurrence after rectal cancer tended to be lower after SILS (0/43 (SILS) vs. 4/35 (OS), $p=0.117)$. Length of stay was significantly shorter after SILS (10 vs. 14 days, $p=0.0004)$. The rate of operations performed by surgical residents was equivalent in both groups (44/80 (SILS) vs. $46 / 80$ (OS), $p=0.75$ ).

Conclusion The data demonstrates that SILS results in similar long-term oncological outcomes when compared to open surgery as well as morbidity rates. The hospital stay in the SILS group was shorter. SILS can also be incorporated in surgical training programmes.
\end{abstract}

Keywords Single access surgery $\cdot$ Minimally invasive surgery $\cdot$ Matched pair $\cdot$ Colon cancer $\cdot$ Rectal cancer

\section{Background}

Minimally invasive surgery has been proven as an accepted alternative to open surgery for the treatment of colorectal cancer [1]. At least oncological non-inferiority has been demonstrated for both colon and rectal cancer

Andreas D. Rink

andreas.rink@unimedizin-mainz.de

1 Department of General, Visceral and Transplant Surgery, University Medicine of Johannes Gutenberg-University, Langenbeckstr 1, 55131 Mainz, Germany

2 Department of General, Visceral and Thoracic Surgery, Leverkusen General Hospital, Am Gesundheitspark 11,

51375 Leverkusen, Germany

3 Department of Surgery, King Edwards VII Memorial Hospital, 7 Point Finger Rd,, Paget DV 04 Hamilton, HM DX, Bermuda surgery, and for patients operated on laparoscopically, earlier postoperative recovery has been demonstrated repeatedly [2, 3]. Single-incision laparoscopic surgery (SILS) has been introduced as a subtype of minimally invasive surgery that further minimizes the surgical trauma [4-6]. The entire operation is performed through one incision which is also used to harvest the surgical specimen in most cases. Some studies have demonstrated additional benefits of this less invasive approach in comparison to multiport laparoscopic surgery (MLS). The benefits are faster postoperative recovery, shorter length of hospital stay, less pain and better cosmetic outcomes [7]. We have published our initial data with intraoperative and early postoperative outcomes in matched cohorts of patients operated on with SILS versus conventional open surgery. The results showed lower morbidity rates and shortened length of hospital stay with SILS patients while the oncological outcomes were equivalent [8]. It is important to note that the effectiveness of SILS with 
oncological patients for the treatment of colorectal cancer in comparison to open or laparoscopic surgery has not been studied sufficiently and there is no long-term data available from well-designed comparable trials.

In order to investigate the oncological safety of SILS for the treatment of colorectal cancer, we performed a matched comparison of early postoperative recovery and long-term oncological outcomes of patients treated with SILS or with open surgery.

\section{Patients and methods}

SILS was introduced at Klinikum Leverkusen for the treatment of benign colorectal diseases in July 2009. SILS experienced consultants expanded their knowledge of this new technique on a selection of patients with colorectal malignancy as an alternative to conventional open surgery. Patients with expected T1-3 tumours were deemed eligible for SILS. The criteria for SILS excluded patients with a body mass index of $>45 \mathrm{~kg} / \mathrm{m}^{2}$, a history of major abdominal surgery with a midline incision and an American Society of Anaesthesiology (ASA) stage > III. All oncological patients operated on up until December 2013 with SILS resection for colorectal adenocarcinoma were included in the analysis and the data was recorded prospectively.

A reliable control group was created out of a cohort of 756 patients who had open surgery for colorectal cancer at Leverkusen General hospital between January 2006 and December 2013. In order to reduce biases, we created a control group matching for the following covariates.

- Tumour localisation

- Right colon

- Transverse colon

- Left colon

- Rectum

- Operative procedure

- Right hemicolectomy

- Transverse colectomy

- Left hemicolectomy or oncologic sigmoid colectomy

- Anterior rectal resection with partial mesorectal excision (PME)

- Sphincter-preserving total mesorectal excision (TME)

- Abdominoperineal excision

- Tumour stage according to the Union internationale contre le cancer (UICC) - classification using the main and subgroups

- Sex
- American Society of Anesthesiologists Score (ASA Score)

- Age category

- 20-40 years

- 41-60 years

- 61-80 years

- $>80$ years

Data from the control patients were collected retrospectively from the clinical information system and the patients' charts.

The primary end point of the study was disease-free survival at 5 years after surgery (5-yDFS). Secondary end points were:

- Overall survival at 5 years

- Oncologic surrogate parameters (lymph node harvest, rstatus, distal resection margins in rectal cancer)

- Morbidity and mortality at 30 days

- Length of hospital stay

\section{Primary surgeons' experience}

The level of surgeon' experience was taken into consideration to investigate potential expert bias. This was done by the procedures being categorised into the following three types.

\section{Expert level procedures}

The primary surgeon was an experienced colorectal surgeon with at least 20 personally performed SILS procedures.

\section{Advanced training operation}

The primary surgeon was a board-certified general or colorectal consultant surgeon with limited experience in SILS. The operation was done under continuous supervision by an experienced colorectal consultant with SILS experience (SILS group) or not necessarily with SILS experience (control group).

\section{Teaching operation}

A surgical resident performed the operation under immediate supervision of an experienced colorectal consultant (open surgery) or an experienced colorectal surgeon with experience of at least 20 personally performed SILS procedures (SILS) 


\section{Surgical technique}

Standard bowel preparation was performed using $30 \mathrm{~g}$ of magnesium sulphate. All procedures were performed under general anaesthesia. A selection of patients received epidural anaesthesia for additional pain control. Patients with left-sided colon or rectal cancer were placed in the lithotomy position and those with cancer at other sites were placed supine. A 3-4-cm umbilical vertical incision was made. In patients likely to require a temporary or permanent stoma, the incision was made at the site of its proposed stoma location. The SILS port was inserted through a wound retractor/protector (Alexis Applied Medical Research Corp., Rancho Santa Margarita, CA) and inserted through the umbilicus. A capnoperitoneum of $14 \mathrm{mmHg}$ was established. Dissection was performed with standard straight laparoscopic instruments (Olympus Key-Med, Southend-on-Sea, Essex, UK) or LigasureTM 5-mm blunt tip sealer (Covidien). A 50-cm-long 30 ${ }^{\circ}$, 5-mm laparoscope (Karl-Storz GmbH \& Co. KG, Tuttlingen, Germany) was used in all cases. From 2009 to 2012, the vessels were dissected with a lateral to medial approach. Starting from 2013, this dissection was preferred to be performed in a medial to lateral approach. The ileocolic and right colic vessels were divided intracorporeally for right colonic resections. In these right colonic resections, the colon was divided in most patients intracorporeally using Endo-GIA (Covidien, Neustadt, Germany) but in all cases the anastomosis was done extracorporeally via stapling or sutured by hand. For left colonic resections, the inferior mesenteric vein was divided at the level of the tail of the pancreas. The inferior mesenteric artery was divided at a point close to the aorta preserving the branches of the superior mesenteric plexus. For left colonic and sphincter-preserving rectal resections, an Endo-GIA was inserted directly through the SILS port without using a trocar and the rectum was divided at the appropriate level. The specimen was extracted via the SILS port incision leaving the wound retractor/protector in place and a double-staple anastomosis was performed. In patients with large tumours or obesity, the incision was expanded to enable a safe harvest of the specimen to avoid tumour contamination. Patients having an abdomino-perineal resection for advanced low rectal cancer had the laparoscopic dissection performed to the mid-rectum so the plane between the rectum and the levator muscle was avoided. The patient was then turned into the prone position and a cylindrical excision was performed as described by Holm et al. [9]. An additional trocar was used if technical difficulties were encountered. If the SILS resection was not possible to perform safely, the procedure was converted to open surgery.

All open operations were done through midline incision.

\section{Follow-up}

Follow-up was performed according to the German guidelines. All patients intended to have SILS procedures had prospectively been collected in a database (IBM SPSS). The follow-up data was also collected prospectively by personally performed, telephone based, or written post-mailed questionnaires at least once a year. The data of the control patients was collected retrospectively. The follow-up examinations (ultrasound, colonoscopy, clinical examination, tumour markers) were partially done by medical practitioners out of the hospital. In these cases, the reports on the findings were requested upon approval of the patients.

\section{Ethics}

Written informed consent concerning the surgical techniques was obtained from all individuals included in this trial. The patients treated with SILS were specifically informed about the new technique and the limited evidence of its use for the treatment of colorectal cancer.

\section{Statistics}

All data were collected and analysed with IBM SPSS Statistics 25. Computer-assisted matching cluster filter applications using Visual Basic 6.0 (Microsoft ADODB Technology) were performed. The data is presented as median and range. The chi-square test was used to compare categorial, and the non-parametric Wilcoxon test for continuous, data, respectively. Survival data were compared with the KaplanMeier method and log rank tests were performed for statistical evaluation. A $p<0.05$ was considered statistically significant. Data analysis was done on an intend-to-treat basis.

\section{Results}

Between January 2006 and December 2013, a total of 910 patients had surgery for colorectal malignancy at Leverkusen General Hospital. The SILS technique was used in 154 cases. In 16 of these cases, SILS was used to perform local excisions or segmented resections for early tumours or for palliative patients. Three of the remaining 138 cases did not have colorectal adenocarcinoma. One patient had surgery for cancer originating from a long standing fistula. Eighty of the remaining 134 patients with oncological SILS resections for colorectal adenocarcinoma perfectly matching control patients regarding the criteria mentioned above (age category, sex, tumour location, tumour stage, surgical procedure, ASA Score) could be identified among the cohort of 756 patients who had open surgery. Forty-six of the patients in each group had rectal cancer and 34 colon cancer. The numbers of patients that 
failed to follow-up 60 months after surgery were 5/80 (6.2\%) in the SILS and 2/80 (2.5\%) in the control group. After 36 months, it was one patient in each group (1.2\%). Overall, the mean follow-up time was 58.8 months in the SILS and 74.3 months in the control group.

The demographics for both groups are presented in Table 1. The patients' body mass index was not used for matching and there was no significant difference in BMI ( $p$ $=0.9$ ) but the proportion of patients with a BMI $>30 \mathrm{~kg} / \mathrm{m}^{2}$ tended to be higher in the control group $(p=0.09)$. An equivalent number of patients had adjuvant treatment.

Table 2 displays the details of the procedures performed in both groups, the primary surgeon's experience and the early postoperative outcomes. The length of stay was significantly shorter after SILS when compared to open surgery. Morbidity tended to be higher in the control group. However, the number of Clavien-Dindo grade IIIb or higher complications were identical with 11/80 severe complications (13.8\%) in each group. There were significantly more expert level operations in the SILS group. However, a similar proportion of the procedures were teaching operations in both groups.

Oncological parameters were equivalent in both groups. There was no significant difference in the use of adjuvant therapy (see Table 3). The oncological long-term outcome is illustrated in Fig. 1a and b. The 5-year disease-free survival were $82 \%$ in the SILS and $70 \%$ in the conventional group $(p=$
$0.11)$. The estimated overall survival at 5 years were $82 \%$ after SILS and $72 \%$ after conventional surgery $(p=0.19)$. Oncological surrogate parameters were distributed equivalently between the two groups. Local recurrence occurred in 4 out of 45 rectal cancer patients in the control group but none in the 43 patients in the SILS group $(p=0.117)$. There was no patient with documented peritoneal carcinomatosis in either group.

\section{Discussion}

Minimally invasive surgery is a well-established treatment for colorectal cancer. Most randomized trials comparing MLS and open surgery resulted in similar oncologic results. The MLS postoperative recovery was faster, the complications less frequent and hospitalisation shorter [2,3]. The COLOR-2-trial has clearly proven the minimally invasive approach for rectal cancer is comparable, while the subgroup of patients with stage III cancers displayed a superior disease-free survival rate [10]. Two studies initially failed to prove non-inferiority as long as oncologic surrogate parameters were investigated [11]. However, the clinical outcome data finally proved to be equivalent $[12,13]$. Thus, minimally invasive surgery for the treatment of rectal cancer has clearly been shown to be successful.

Table 1 Basic characteristics

\begin{tabular}{|c|c|c|c|c|}
\hline & & SILS & Control & $p$ \\
\hline \multicolumn{2}{|l|}{$\operatorname{Sex}(f / m)(n)$} & $20 / 60$ & $20 / 60$ & 1 \\
\hline \multicolumn{2}{|l|}{ Age } & $67.7(43-87)$ & $66.1(35-85)$ & 0.168 \\
\hline \multicolumn{2}{|l|}{ BMI $\left(\mathrm{kg} / \mathrm{m}^{2}\right)$} & $25.4(19-34)$ & $27.3(18-43)$ & 0.9 \\
\hline \multicolumn{2}{|c|}{ Obesity $\left(\mathrm{BMI} \geq 30 \mathrm{~kg} / \mathrm{m}^{2}\right)(n(\%))$} & $10 / 80$ & $23 / 80$ & 0.09 \\
\hline \multicolumn{2}{|c|}{ ASA Score I/II/III/IV/V (n) } & $8 / 40 / 29 / 3 / 0$ & $8 / 40 / 29 / 3 / 0$ & 1 \\
\hline \multirow[t]{8}{*}{ Tumour location } & Coecum & 3 & 3 & \multirow[t]{8}{*}{1} \\
\hline & Ascending colon & 8 & 8 & \\
\hline & Transverse colon & 1 & 1 & \\
\hline & Descending colon & 2 & 2 & \\
\hline & Sigmoid colon & 20 & 20 & \\
\hline & Upper rectum $(12-16 \mathrm{~cm})$ & 19 & 19 & \\
\hline & Mid rectum $(>6-12 \mathrm{~cm})$ & 16 & 16 & \\
\hline & Lower rectum $(0-6 \mathrm{~cm})$ & 11 & 11 & \\
\hline \multirow[t]{8}{*}{ UICC stage* } & 0 & 4 & 4 & \multirow[t]{8}{*}{1} \\
\hline & I & 20 & 20 & \\
\hline & IIA & 18 & 18 & \\
\hline & $\mathrm{IIb}$ & 1 & 1 & \\
\hline & IIIA & 5 & 5 & \\
\hline & IIIB & 24 & 24 & \\
\hline & IIIC & 4 & 4 & \\
\hline & IVA & 4 & 4 & \\
\hline
\end{tabular}

*Postoperative pathologic staging 
Table 2 Procedures and early postoperative outcome

\begin{tabular}{|c|c|c|c|c|}
\hline & & $\operatorname{SILS}(n=80)$ & Control $(n=80)$ & $p$ \\
\hline \multicolumn{5}{|l|}{ Type of surgery } \\
\hline \multicolumn{2}{|l|}{ Right hemicolectomy } & 11 & 11 & 1 \\
\hline \multicolumn{2}{|l|}{ Transverse colectomy } & 1 & 1 & \\
\hline \multicolumn{2}{|l|}{ Left hemicolectomy or sigmoid colectomy } & 19 & 19 & \\
\hline \multicolumn{2}{|l|}{ Anterior rectal resection (PME) } & 21 & 21 & \\
\hline \multicolumn{2}{|l|}{ Low anterior resection (TME) } & 22 & 22 & \\
\hline \multicolumn{2}{|l|}{ Abdomino-perineal resection } & 7 & 7 & \\
\hline \multicolumn{5}{|l|}{ Other technical aspects } \\
\hline \multicolumn{2}{|l|}{ Duration of surgery (min) } & $227(97-500)$ & $192(59-543)$ & 0.1 \\
\hline \multicolumn{2}{|l|}{ Conversion to open surgery } & $11(13.8 \%)$ & - & - \\
\hline \multicolumn{2}{|l|}{ One additional trocar } & $5(6.2 \%)$ & & - \\
\hline \multicolumn{2}{|l|}{ Surgeons' experience (expert/advanced training/teaching) } & $30 / 6 / 44$ & $16 / 18 / 46$ & 0.002 \\
\hline \multicolumn{5}{|l|}{ Morbidity } \\
\hline \multirow{7}{*}{$\begin{array}{l}\text { Patients with at least one complication } \\
\text { Classification of morbidity according to Clavien-Dindo }\end{array}$} & & $27 / 80$ & $43 / 80$ & 0.274 \\
\hline & I & 3 & 10 & \\
\hline & II & 9 & 19 & \\
\hline & IIIA & 4 & 3 & \\
\hline & IIIB & 9 & 9 & \\
\hline & IV & 1 & 1 & \\
\hline & $\mathrm{V}$ & 1 & 1 & \\
\hline \multicolumn{2}{|l|}{ Length of stay (days) } & $10(4-57)$ & $14(1-81)$ & 0.0004 \\
\hline
\end{tabular}

The single-incision approach is the least invasive version of laparoscopic surgery. SILS is considered to further reduce postoperative pain and improve recovery when compared to open surgery [7]. However, the technique can be technically challenging. Most surgeons use standard straight laparoscopic instruments. The lack of triangulation and the need for parallel positioning can make adequate dissection challenging. A total of five randomized controlled trials comparing SILS versus MLS for the treatment of colorectal cancer have been published [14-18]. In summary, these trials demonstrate that SILS for colorectal cancer can be used safely but has no clear advantage over MLS.

We directly compared SILS with open surgery and found that SILS was associated with a significant shorter hospital stay; however, the median length of stay was long in both groups. The primary reason for this is the patients' expectation of hospitalisation in Germany and their health insurances

Table 3 Oncologic surrogates and adjuvant treatment

\begin{tabular}{llll}
\hline Lymph node harvest & $20(7-41)$ & $21(1-61)$ & 0.731 \\
\hline $\begin{array}{l}\text { Distal resection margin [cm] (rectal } \\
\quad \text { cancer) }\end{array}$ & $5(1.3-7)$ & $5(2-6.5)$ & 1 \\
R0-resection & $80 / 80$ & $80 / 80$ & 1 \\
Postoperative adjuvant chemotherapy & $48 / 80$ & $45 / 80$ & 0.633 \\
\hline
\end{tabular}

completely cover all expenses of in-hospital stay. Regardless, the less invasive procedure resulted in a significant reduction of hospitalisation. Complications occurred slightly less frequently in the SILS group. This finding is consistent with the result of our earlier published matched pair comparison of patients treated for colorectal cancer by SILS versus open surgery [8]. The subgroup of patients with colon cancer had fewer wound complications in our previous trial. However, in our recent trial, the difference of severe wound complications was not significant and the incidence was the same in both groups. The analysed cohorts in our former trial were not identical to those investigated in the recent one. In the recent analysis, we made extensive efforts to have equivalent oncological groups of patients. We expanded the cohort of patients with open surgery to a total of more than 750 cases. In 80 of the patients operated on for colorectal cancer, we were able to find perfectly matched controls based on tumour location, tumour stage, mode of surgery and significant risk factors. We found identical oncological candidates and we could not find any significant differences in the oncological longterm outcomes. There was a trend for more successful results in the SILS group (5y-DFS 82 vs $70 \%(p=0.11)$, and 0 versus 4 local recurrences after surgery for rectal cancer ( $p=$ $0.117)$, respectively). It needs to be taken into account that almost $14 \%$ of the SILS intended operations were converted to open surgery. In an additional $6.2 \%$ of the patients, one additional trocar was used. The conversion rate is in line with 

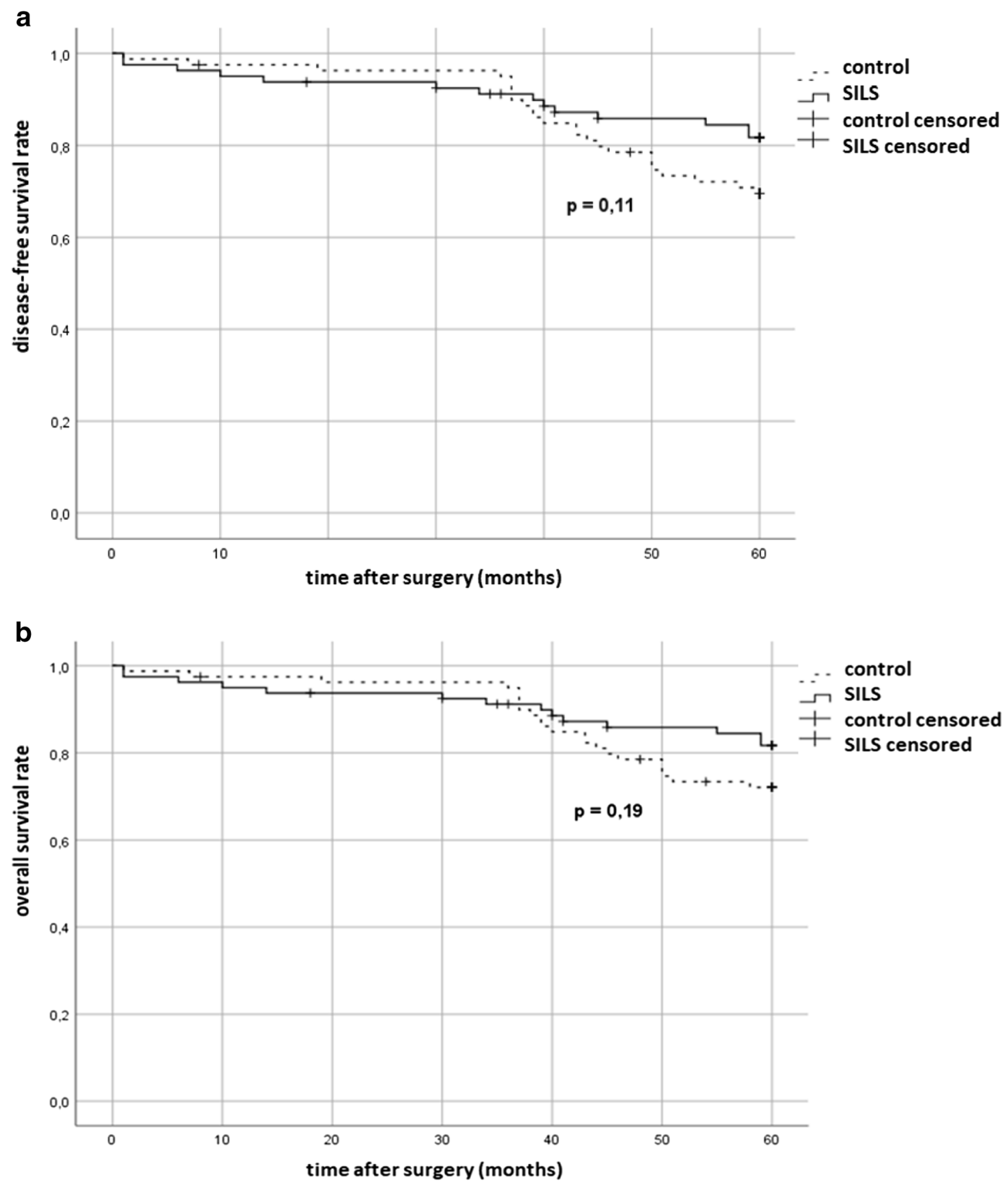

Fig. 1 a Disease-free survival after SILS or conventional surgery for colorectal cancer. b Overall survival after SILS or conventional surgery for colorectal cancer

data from other series on patients treated with minimally invasive surgery for colorectal cancer recruited in the beginning of the last decade [19]. The rather liberal conversion to open surgery in our cohort might in part be responsible for the $100 \%$ R0 resection rate and might also have slightly influenced the presented oncological candidate parameters.

Furthermore, in spite of the high rate of more than 50\% teaching operations in both groups, SILS procedures were performed more frequently by more experienced consultants. Some degree of expert bias might have influenced the results as selection bias might have done. The patients that were not considered to be suitable for SILS for any reason were treated by open surgery. In spite of the fact that the median BMI was not significantly different between the two groups, it seems that patients with a BMI $\geq 30 \mathrm{mg} / \mathrm{m}^{2}$ were more likely to have been treated by open surgery, although this difference was not 
statistically significant. Regardless, the data indicate at least oncologic non-inferiority of SILS in comparison with open surgery in selected patients.

Our data also shows that SILS is not exclusively successful when performed by laparoscopic experts only. A substantial amount of these procedures had been done by residents or by newly qualified consultants with limited experience in minimally invasive colorectal surgery under the supervision of an expert surgeon. This suggests that the SILS technique was thoroughly integrated in the surgical training in our hospital. It is important to note that the residents were not in the beginning of their laparoscopic training. Before doing the first colorectal procedure, they had gained minimally invasive surgery experience by having performed up to 200 laparoscopic general surgery cases like cholecystectomies, appendectomies and hernia repairs. Colorectal cancer procedures and SILS can be included in the surgical residents' teaching programmes.

One disadvantage of SILS is that the duration of the surgery tends to be longer, although the difference is $35 \mathrm{~min}$. The median durations failed to reach significance due to the wide range of the values.

\section{What is the future relevance of SILS for the treatment of colorectal cancer?}

Based on the recent literature, SILS has no clear benefit over MLS in the treatment of colorectal cancer. Two recent systematic reviews and meta-analyses found better oncological outcomes, lower complication rates, less pain, earlier recovery and less blood loss when comparing SILS with multiport laparoscopy $[20,21]$. However, a majority of trials included in these reviews were non-randomized cohort trials with a high risk of both selection and expert bias. MLS however is easier. The unrestricted option of trocar placement does not only enable a more comfortable exposure and dissection but might also be helpful to achieve perfect specimens more easily and to improve oncological outcomes.

The next generation of robotic surgery in the future will enable surgeons to do single-incision surgery in a more comfortable setting by having a 3-dimensional view, adequate triangulation and facilities to comfortably suture intracorporal anastomoses [22, 23]. These robotic systems will provide the opportunity to choose the best site for the incision considering postoperative pain, acceleration of recovery and minimizing the risk of incision hernia while still harvesting a perfect oncological specimen. This may result in SILS being discussed as an attractive alternative to multiport laparoscopic surgery in the future.

Funding Open Access funding enabled and organized by Projekt DEAL.

\section{Declarations}

Ethics approval and informed consent Written informed consent concerning the surgical techniques was obtained from all individuals included in this trial. The patients treated with SILS were specifically informed about the limited evidence of the new technique. All patients treated since July 2009 gave prospectively informed consent for the use of their data for scientific purposes. Patients treated before 2009 in the control group were asked for consent retrospectively by telephone.

Conflict of interest The authors declare no competing interests.

Open Access This article is licensed under a Creative Commons Attribution 4.0 International License, which permits use, sharing, adaptation, distribution and reproduction in any medium or format, as long as you give appropriate credit to the original author(s) and the source, provide a link to the Creative Commons licence, and indicate if changes were made. The images or other third party material in this article are included in the article's Creative Commons licence, unless indicated otherwise in a credit line to the material. If material is not included in the article's Creative Commons licence and your intended use is not permitted by statutory regulation or exceeds the permitted use, you will need to obtain permission directly from the copyright holder. To view a copy of this licence, visit http://creativecommons.org/licenses/by/4.0/.

\section{References}

1. Pox CP, Schmiegel W (2013) German S3-guideline colorectal carcinoma. Dtsch Med Wochenschr 138(49):2545

2. Fürst A, Heiligensetzer A, Sauer P, Liebig-Hörl G (2015) Scientific evidence for laparosopic rectal cancer surgery. Coloproctology 37(2):97-102

3. Schwenk W, Neudecker J, Haase O (2015) Evidenzlage der laparoskopischen Chirurgie beim Kolonkarzinom. Current evidence for laparoscopic surgery of colonic cancer. Coloproctology. 37(6):381-390

4. Vestweber B, Galetin T, Lammerting K, Paul C, Giehl J, Straub E, Kaldowski B, Alfes A, Vestweber KH (2013) Single-incision laparoscopic surgery: outcomes from 224 colonic resections performed at a single center using SILS. Surg Endosc 27(2):434-442

5. Bucher P, Pugin F, Morel P (2008) Single port access laparoscopic right hemicolectomy. Int J Color Dis 23(10):1013-1016

6. Leroy J, Cahill RA, Asakuma M, Dallemagne B, Marescaux J (2009) Single-access laparoscopic sigmoidectomy as definitive surgical management of prior diverticulitis in a human patient. Arch Surg 144(2):173-179 discussion 9

7. Markar SR, Wiggins T, Penna M, Paraskeva P (2014) Singleincision versus conventional multiport laparoscopic colorectal surgery-systematic review and pooled analysis. J Gastrointest Surg 18(12):2214-2227

8. Rink AD, Vestweber B, Paul C, Vestweber KH (2015) Singleincision laparoscopic surgery for colorectal malignancy-results of a matched-pair comparison to conventional surgery. Int J Color Dis 30(1):79-85

9. Holm T, Ljung A, Haggmark T, Jurell G, Lagergren J (2007) Extended abdominoperineal resection with gluteus maximus flap reconstruction of the pelvic floor for rectal cancer. Br J Surg 94(2): 232-238

10. Bonjer HJ, Deijen CL, Abis GA, Cuesta MA, van der Pas MH, de Lange-de Klerk ES et al (2015) A randomized trial of laparoscopic versus open surgery for rectal cancer. N Engl J Med 372(14):13241332 
11. Spinelli A, D'Hoore A, Panis Y, Bemelman WA, Jayne DG, Fürst A (2017) Critical appraisal of two randomized clinical trials on pathologic outcomes. Colorpctology 39:277

12. Stevenson ARL, Solomon MJ, Brown CSB, Lumley JW, Hewett P, Clouston AD, Gebski VJ, Wilson K, Hague W, Simes J, Australasian Gastro-Intestinal Trials Group (AGITG) ALaCaRT investigators (2019) Disease-free survival and local recurrence after laparoscopic-assisted resection or open resection for rectal cancer: The Australasian Laparoscopic Cancer of the Rectum Randomized Clinical Trial. Ann Surg 269(4):596-602

13. Fleshman J, Branda ME, Sargent DJ, Boller AM, George VV, Abbas MA, Peters WR, Maun DC, Chang GJ, Herline A, Fichera A, Mutch MG, Wexner SD, Whiteford MH, Marks J, Birnbaum E, Margolin DA, Larson DW, Marcello PW, Posner MC, Read TE, Monson JRT, Wren SM, Pisters PWT, Nelson H (2019) Diseasefree survival and local recurrence for laparoscopic resection compared with open resection of stage ii to iii rectal cancer: follow-up results of the ACOSOG Z6051 randomized controlled trial. Ann Surg 269(4):589-595

14. Kang BM, Kim HJ, Kye BH, Lee SC, Lee KY, Park SJ, Lee SH, Lim SW, Lee YS, Kim JH, Lee J, Kim MK, Kim JG (2018) Multicenter, randomized single-port versus multiport laparoscopic surgery (SIMPLE) trial in colon cancer: an interim analysis. Surg Endosc 32(3): 1540-1549

15. Kang BM, Park SJ, Lee KY, Lee SH (2017) Single-port laparoscopic surgery can be performed safely and appropriately for colon cancer: short-term results of a pilot randomized controlled trial. J Laparoendosc Adv Surg Tech Part A 27(5):501-509

16. Watanabe J, Ota M, Fujii S, Suwa H, Ishibe A, Endo I (2016) Randomized clinical trial of single-incision versus multiport laparoscopic colectomy. Br J Surg 103(10):1276-1281

17. Poon JT, Cheung CW, Fan JK, Lo OS, Law WL (2012) Singleincision versus conventional laparoscopic colectomy for colonic neoplasm: a randomized, controlled trial. Surg Endosc 26(10): 2729-2734

18. Huscher CG, Mingoli A, Sgarzini G, Mereu A, Binda B, Brachini G, Trombetta S (2012) Standard laparoscopic versus single-incision laparoscopic colectomy for cancer: early results of a randomized prospective study. Am J Surg 204(1):115-120

19. de Neree Tot Babberich MPM, van Groningen JT, Dekker E, Wiggers T, Wouters M, Bemelman WA et al (2018) Laparoscopic conversion in colorectal cancer surgery; is there any improvement over time at a population level? Surg Endosc 32(7): 3234-3246

20. Zhao GH, Wang H, Yu H, Sun J, Zhao C, Liu Y, Xiong J, Chang J, Wang M, Wang W, Ye D, Zhou H, Yu T (2019) A systematic review of comparing single-incision versus traditional laparoscopic right hemicolectomy for right colon diseases. Surg Laparosc Endosc Percutaneous Techn 29(6):417-425

21. Liu X, Li JB, Shi G, Guo R, Zhang R (2018) Systematic review of single-incision versus conventional multiport laparoscopic surgery for sigmoid colon and rectal cancer. World J Surg Oncol 16(1):220

22. Salem JF, Agarwal S, Schoonyoung H, Martin C, Marks JH (2020) Initial clinical experience with Single-Port robotic (SP r) left colectomy using the SP surgical system: description of the technique. Surg Endosc

23. Marks JH, Kunkel E, Salem J, Martin C, Schoonyoung HP, Agarwal S (2020) rSILS: initial clinical experience with singleport robotic (SPr) right colectomy. Tech Coloproctol 24(8):817822

Publisher's note Springer Nature remains neutral with regard to jurisdictional claims in published maps and institutional affiliations. 